\title{
Incident prediabetes/diabetes and blood pressure in urban and rural communities in the Democratic Republic of Congo
}

This article was published in the following Dove Press journal:

Vascular Health and Risk Management

21 July 20II

Number of times this article has been viewed

\author{
Joyce D Hightower' \\ C Makena Hightower ${ }^{2}$ \\ Beatriz Y Salazar Vázquez ${ }^{2,3}$ \\ Marcos Intaglietta ${ }^{2}$ \\ 'Department of Health Projects, \\ Kinshasa, Democratic Republic \\ of Congo; ${ }^{2}$ Department of \\ Bioengineering, University of \\ California, San Diego, CA, USA; \\ ${ }^{3}$ Facultad de Medicina, Universidad \\ Juárez del Estado de Durango, \\ Durango, México
}

Background: The Democratic Republic of Congo (DRC) faces increased morbidity and mortality due to treatable and preventable noncommunicable diseases. However, it continues to struggle with political and economic instability, which impedes much needed health infrastructure improvements. The present study was designed as a low-cost determination of the prevalence of incident prediabetes/diabetes in the DRC.

Method: Fasting blood glucose, body mass index, blood pressure, and age were assessed in adult participants in health screenings conducted throughout urban and rural DRC. Communities were divided into three categories, based on physical activity (means of transport) and diet, ie, traditional (nonmotorized transport and vegetable/starch-based diets); transitional (incorporating traditional practices with motorized transport) and modern (motorized transport and protein/ processed foods). Fasting blood glucose and blood pressure were established using finger prick blood samples and monitors approved by the US Food and Drug Administration.

Results: The prevalence of incident prediabetes/diabetes was over $47 \%$ for the traditional population, $88.6 \%$ for the transitional population, and $91.4 \%$ for the modern communities. Fasting blood glucose levels analyzed through an analysis of covariance, with age and body mass index as covariates, demonstrated that fasting blood glucose levels of male and female subgroups in the traditional community $(101.8 \pm 29.3 \mathrm{mg} / \mathrm{dL}$ and $95.4 \pm 27.8 \mathrm{mg} / \mathrm{dL}$, respectively), were significantly reduced compared with the transitional $(122.1 \pm 19.4 \mathrm{mg} / \mathrm{dL}$ and $122.8 \pm 23.9 \mathrm{mg} / \mathrm{dL})$, and modern $(118.8 \pm 15.9 \mathrm{mg} / \mathrm{dL}$ and $114.1 \pm 17.1 \mathrm{mg} / \mathrm{dL})$ populations. Additionally, for the male and female subgroups, logistic regression analysis confirmed a significant association between incident prediabetes/diabetes, fasting blood glucose, diet, and level of physical activity.

Conclusion: There is a higher than expected prevalence of incident prediabetes/diabetes in the DRC adult population, without a clear association with risk factors pertaining to diet, level of physical activity, body mass index, and blood pressure. The substantial morbidity and mortality associated with diabetes highlights the critical need for further and more precise diabetic diagnostic testing throughout the DRC.

Keywords: fasting blood glucose, incident diabetes, Democratic Republic of Congo, urban, rural

\section{Introduction}

Diabetes mellitus type 2 (DMT2) is a noncommunicable and treatable disease and is often a preventable cardiovascular risk factor. However, newly diagnosed DMT2 cases are steadily increasing in both developing and developed countries, which is well documented in both the popular and scientific literature. Although the etiology of the disease has not yet been fully characterized, most investigations conclude that 
advancement of the disease is in part due to the genetics of certain populations, ${ }^{1,2}$ changes in nutritional habits, ${ }^{1,3}$ increased intake of calories from foods high in simple sugars, edible fats, and cholesterol, with decreased fiber intake ${ }^{4}$ and caloric expenditure. Due to the great abundance and supply of nutrient-poor and calorie-rich foods in developing countries, estimates predict that by 2025 the largest increases in DMT2 will take place in these countries, ${ }^{5}$ principally in Africa and Asia. ${ }^{6}$ Unfortunately, due to their lack of modern health care and other basic infrastructure, these countries are left seemingly defenseless against the catastrophic morbidity and mortality that awaits them.

Rotimi et al reported results of their search for type 2 diabetes susceptibility genes ${ }^{7}$ according to findings from the Africa America Diabetes Mellitus study. However, this information is difficult to correlate with the incidence of DTM2 because the developing world's health status is not well known, which can lead to anomalous interpretations of the causes of the disease.$^{8-10}$ Clinical diagnostic investigations are being completed to help characterize the prevalence and incidence of DMT2 in rural and urban sub-Saharan African communities. ${ }^{8,11-13}$ However, such studies and subsequent treatment efforts are hindered due to the scarcity of equipment and supplies, and the burden of inaccessibility, specifically when communities may be inaccessible as a result of real and/or investigator perceived insecurity.

The political stabilization of Africa is leading to the construction of roads, and establishing connections with previously isolated populations having distinctive backgrounds and lifestyles. The sudden access to these previously isolated groups provides unique opportunities for analyzing the effects of lifestyle changes in comparatively homogenous populations, particularly regarding differences in the preponderance of DMT2, which is in part attributed to the transition from a native to a modernized diet and lifestyle. ${ }^{3}$ The Democratic Republic of Congo (DRC), the third largest country on the African continent, continues to struggle with political and economic instability, and therefore, infrastructure development and receipt of external help towards treatment and prevention of life-threatening noncommunicable diseases is limited.

The present analysis was designed as a low-cost method to determine the prevalence of incident prediabetes and diabetes (a single measurement of fasting blood glucose 100 to $125 \mathrm{mg} / \mathrm{dL}$ or fasting blood glucose $>125 \mathrm{mg} / \mathrm{dL}$, respectively) in the DRC, as an indication of the need for more rigorous diabetic diagnostic testing and corresponding treatment. Specifically, this study analyzes a database of information to assess whether a clinically significant difference in fasting blood glucose and calculated body mass index collected during free public health screenings carried out in DRC communities was associated with the level of westernization of diet and lifestyle. In view of the significant role that hypertension plays in the regulation of diabetes, ${ }^{14}$ we also examined blood pressure levels.

\section{Materials and methods}

Health screenings took place in April-August 2004. Participants were voluntary adults, male and female, over 18 years of age, from the general population living and working within the area surrounding the health screening examination sites. All participants provided informed consent at the time of their visit prior to examination. Advertisements for participation in the screenings included instructions to fast overnight ( $8-10$ hours), ingesting only water prior to arriving for testing. Registration and completion of health history questionnaires by participants confirmed the 8-10-hour fast. Appointed health care screening staff referred participants with abnormal fasting blood glucose results and/or blood pressures, based on the American Diabetic Association standards $^{6}$ and the Seventh Joint National Committee Criteria, ${ }^{15}$ respectively, to local physicians and clinics for secondary testing and necessary treatment.

\section{Inclusion criteria}

Data were collected during free health care screenings in the following communities and close surrounding areas: Mampu ( $\mathrm{n}=193)$, Kisangani $(\mathrm{n}=351)$, Ngiri Ngiri $(n=54)$, and Mount Ngafula $(n=269)$. Inclusion of subject results followed inspection of completed health history questionnaires. Exclusion criteria were current conditions of malaria or other blood diseases, pregnancy, lactation, and major surgery within 6 months prior to screening. The Minister of Health and the health zone chief of each DRC community approved the procedures.

\section{Health care screening methodology and biochemistry}

At each location, health screening staff, nurses, and experienced technical personnel were supervised by medical practitioners. Participant registration and health history questionnaire completion was conducted by trained nurses working at local clinics. Experienced laboratory technical personnel were responsible for finger prick blood draws and fasting blood glucose measurements. Fasting blood glucose levels were measured using a blood glucose system 
(OneTouch Ultra 2, donated by LifeScan), approved for glucose testing by the US Food and Drug Administration. Blood pressures, taken prior to blood sample collection, were measured using battery-operated automatic blood pressure monitors, also approved by the US Food and Drug Administration. Pulse pressure was determined as the difference in systolic and diastolic blood pressure. Mean arterial pressure was determined using equation 1 , where P stands for pressure:

$$
\text { Mean arterial pressure }=\mathrm{P}_{\text {diastolic }}+\frac{1}{3\left(\mathrm{P}_{\text {systolic }}-\mathrm{P}_{\text {diastolic }}\right)}
$$

Registration and completion of the health questionnaire included age, gender, blood pressure, heart rate, and anthropometric parameters, as well as the dominant method of transport to work or school. Information regarding the participants' method of transport to work or school provided data on their levels of daily physical activity.

\section{Community division classifications}

Communities were characterized according to their level of western influence on diet (ie, number and content of meals) and/or lifestyle (ie, physical activity level, as determined by the method of transportation to and from work or school), at the time of health screenings. Mampu and the surrounding areas were categorized as traditional, having little to no western/modern influence, Kisangani and Ngiri Ngiri were categorized as transitional, having been influenced, to some extent, in both diet and lifestyle, and Mount Ngafula, a major suburb of Kinshasa, the capital and largest city of the DRC, was the modern community. Information about diet and lifestyle, ie, exercise practices/physical activity of each data collection site was obtained from individual health questionnaire responses, facilitated by native speakers, and direct observation during time spent in each area before, during, and after the days of collection.

Participants from the traditional category typically eat only two meals per day. Their morning meal consists of tea, with sugar, and canned or powdered milk. Their evening meal consists of cassava (Manihot esculenta) leaves, cooked with palm oil, and fufu (a stiff porridge made from the starchy cassava tuber flour). ${ }^{16}$ Travel to and from work or school is by foot or nonmotorized bicycle, with an average distance exceeding $1 \mathrm{~km}$.

Participants of the transitional category also typically eat only two meals per day. Their morning meal consists of tea, with milk and sugar, and white bread, sometimes with the addition of margarine. Their evening meal consists of cassava leaves in palm oil and fufu. Two to three times per week there is an addition of fish or chicken in a tomato-based sauce ${ }^{17}$ and other leafy vegetables, such as bitekuteku (a green leafy vegetable resembling cooked spinach leaves in appearance) and ngayi-ngayi (Hibiscus sabdariffa). Occasionally, they may also add beans and white rice to their evening meal.

Travel to and from work or school is accomplished through a combination of motorized vehicle transportation from a station closest to their home to the station nearest their destination and a less than $0.25 \mathrm{~km}$ walk from home or destination to each station.

Participants from the modern category routinely eat three meals daily. Their morning meal consists of tea, with milk and sugar, white bread, eggs, and processed meats. Their midday meal is composed of fried potatoes, processed meats, and a $250 \mathrm{~mL}$ container of processed or carbonated sugary drink. Their evening meal consists of a variety of alternating foods, including cassava leaves cooked with palm oil or other green leafy vegetables, bitekuteku or ngayi-ngayi, fufu, potatoes, beans, or white rice. Three to four times per week a portion of meat, poultry, or fish is included in the meal. ${ }^{17}$ Travel to and from work or school is entirely by motorized vehicle.

\section{Data analysis}

Statistical analysis was completed using Systat 13 (Systat Software Inc, Chicago, IL). Fasting blood glucose and pulse pressure were analyzed as both continuous and categorical variables. Analysis of covariance was used to compare the means of the continuous variables, ie, fasting blood glucose, mean arterial pressure, systolic and diastolic blood pressure, and pulse pressure according to westernization of diet and/ or lifestyle, with age and body mass index as covariates; subsequent pairwise comparisons were made between communities using Bonferroni's post test. Bonferroni's pairwise post test was also used to compare the means of body mass index as a continuous variable, with age as a covariate. Differences were considered significant at $P<0.05$. Fasting blood glucose, pulse pressure, and body mass index were dichotomized according to incident prediabetic/diabetic status (fasting blood glucose $\geq 100$ or $<100$ ), pressure levels (pulse pressure $\geq 50$ or $<49$ ), and body mass (body mass index $\geq 29.9$ or $<29.9$ ), respectively. A logistic regression was used to provide odds ratios for the categorical variables, ie, fasting blood glucose, pulse pressure, and body mass index according to diet and/or westernized lifestyle. Due to variations in the percentages of females that made up each community, data for male and female subjects were analyzed separately. 


\section{Results}

Data from the traditional community, Mampu, included 193 individuals (mean age 35.5 years), having an incident prediabetes/diabetes diagnosis for over $47 \%$ of the subjects. The same analysis completed for the transitional communities of Kisangani and Ngiri Ngiri data included 405 individuals (mean age 42.3 years) and resulted in an $88.6 \%$ incident prediabetes/diabetes diagnosis. In addition, an analysis of data for 269 individuals (mean age 43.2 years) from the modern community of Mount Ngafula revealed a $91.4 \%$ rate of incident prediabetes/diabetes.

The means and standard deviations of the measured parameters, according to community classification, are presented in Tables 1A and 1B. Analysis of both the male and female data confirmed significant differences between the communities $(P<0.05)$. However, the female population had a greater number of significant differences in key health parameters, fasting blood glucose, body mass index, and pulse pressure (Table 1B).

The odds ratios for fasting blood glucose, pulse pressure, and body mass index, according to diet and/or life style westernization are listed in Table 2 . In both the male and female populations, the odds ratios showed that a westernized diet and/ or life style is a significant risk for incident prediabetes/diabetes diagnosis. Additionally, an equally significant risk was present for obesity in the female population (Table 2).

\section{Discussion}

The principal result of this study is that there is a higher than expected prevalence of incident prediabetes/diabetes within each of the traditional, transitional, and modern communities in DRC. Additionally, there is a significant difference in the prevalence of incident prediabetes/diabetes, constituting a prominent risk, in male and female populations exposed to a westernized diet and/or lifestyle. Consequently, this cardiovascular risk factor may not be due to the introduction to a modern or westernized diet and/or lifestyle, but instead augmented by such a change.

Fasting blood glucose levels were elevated significantly in the traditional community category, without exposure to modern influences in diet or lifestyle, ie, reduced physical activity. Prenatal and childhood nutritional deficiency has been linked to metabolic dysfunction and disease in later adult life. ${ }^{18}$ There also exists the possibility of liver damage and/ or impaired vasculature, disrupting insulin activity and end organ glucose uptake, due to recurrent malarial infections. Small changes in hematocrit, such as those associated with malarial hemolysis, disrupt vascular control ${ }^{19}$ and may gradually lead to microvascular dysfunction associated with DMT2. Although presently untested, these may be important factors in our anomalous observations.

Additionally, damage to the insulin-producing pancreas may arise from the main dietary staple of the traditional community in the DRC, which is nearly devoid of protein. ${ }^{16,17}$ Digestion of cassava leaves and tubers releases cyanide and predisposes consumers to pancreatotoxicity in proportion to the degree of malnutrition. ${ }^{20}$

Our findings disagree, in part, with the previously published Pima Indian study, describing the effect of environment on DMT2 and obesity. ${ }^{3}$ Contrasting a comparatively traditional community with a westernized population of similar ancestry, Schulz et al reported an increased prevalence and incidence of DMT2 following changes in the environment that paralleled the rise in obesity. ${ }^{3}$ The authors contend that although genetics may predispose some populations to diabetes, it is not inevitable, and can be prevented by avoiding obesity, through environmental regulation and proper caloric intake and expenditure. ${ }^{3}$

These previous contentions do not explain the results of the present study. Obese individuals (body mass

Table I A Demographic characteristics for men in traditional, transitional, and modern communities of the Democratic Republic of Congo

\begin{tabular}{|c|c|c|c|c|c|c|}
\hline & \multicolumn{2}{|l|}{$\underline{\text { Traditional }}^{\mathrm{a}}$} & \multicolumn{2}{|c|}{ Transitional $^{\mathrm{b}}$} & \multicolumn{2}{|l|}{ Modern ${ }^{c}$} \\
\hline & Mean \pm SD & $P^{\prime}$ & Mean \pm SD & $P^{2}$ & Mean \pm SD & $P^{3}$ \\
\hline Age, years & $35.8 \pm 9.4$ & $<0.00 \mathrm{I}$ & $42.7 \pm 13.2$ & 1.0 & $44.0 \pm 12.7$ & $<0.001$ \\
\hline $\mathrm{BMI}, \mathrm{kg} / \mathrm{m}^{2}$ & $22.0 \pm 3.2$ & 0.45 & $22.8 \pm 4.2$ & 1.0 & $22.8 \pm 4.9$ & 0.57 \\
\hline $\mathrm{FBG}, \mathrm{mg} / \mathrm{dL}$ & $101.8 \pm 29.3$ & $<0.001$ & $122.1 \pm 19.4$ & 0.71 & $118.8 \pm 15.9$ & $<0.001$ \\
\hline MAP, $\mathrm{mmHg}$ & $93.1 \pm 10.3$ & 1.0 & $96.2 \pm 17.0$ & 1.0 & $95.1 \pm 14.0$ & 1.0 \\
\hline Systolic BP, mmHg & $127.5 \pm 15.7$ & 0.60 & $\mid 28.1 \pm 21.8$ & 1.0 & $129.7 \pm 21.0$ & 1.0 \\
\hline Diastolic BP, mmHg & $75.9 \pm 9.9$ & 0.18 & $80.2 \pm 16.4$ & 0.37 & $77.8 \pm 13.5$ & 1.0 \\
\hline Pulse pressure, $\mathrm{mmHg}$ & $51.6 \pm 13.4$ & $<0.001$ & $47.9 \pm 15.0$ & 0.15 & $51.9 \pm 18.1$ & 0.62 \\
\hline
\end{tabular}

Notes: Population $\mathrm{n}$ (incident prediabetes/diabetes percentage): ${ }^{1}|2|$ (48.8\%), ${ }^{\circ}|6|$ (90.7\%), ${ }^{c} \mid 05$ (96.2\%). Analysis of covariance, Bonferroni's post test: $P^{1}$ traditional versus transitional; $P^{2}$ transitional versus modern; $P^{3}$ modern versus traditional.

Abbreviations: SD, standard deviation; BMI, body mass index; FBG, fasting blood glucose; MAP, mean arterial pressure; BP, blood pressure. 
Table I B Demographic characteristics for women in traditional, transitional, and modern communities of the Democratic Republic of Congo

\begin{tabular}{|c|c|c|c|c|c|c|}
\hline & \multicolumn{2}{|l|}{ Traditional $^{\mathrm{x}}$} & \multicolumn{2}{|c|}{ Transitionaly ${ }^{y}$} & \multicolumn{2}{|l|}{ Modern ${ }^{z}$} \\
\hline & Mean \pm SD & $P^{\prime}$ & Mean \pm SD & $P^{2}$ & Mean \pm SD & $P^{3}$ \\
\hline Age, years & $34.9 \pm 12.6$ & $<0.001$ & $42.0 \pm 13.0$ & 1.0 & $42.7 \pm 13.0$ & $<0.001$ \\
\hline $\mathrm{BMI}, \mathrm{kg} / \mathrm{m}^{2}$ & $21.8 \pm 2.8$ & $<0.001$ & $24.0 \pm 4.6$ & 0.20 & $24.9 \pm 5.4$ & $<0.001$ \\
\hline $\mathrm{FBG}, \mathrm{mg} / \mathrm{dL}$ & $95.4 \pm 27.8$ & $<0.001$ & $122.8 \pm 23.9$ & $<0.001$ & $1 \mid 4.1 \pm 17.1$ & $<0.001$ \\
\hline MAP, mmHg & $93.1 \pm 13.9$ & 1.0 & $96.9 \pm 15.9$ & 0.43 & $95.5 \pm 16.1$ & 0.88 \\
\hline Systolic BP, mmHg & $124.2 \pm 22.5$ & 0.52 & $127.0 \pm 23.6$ & 1.0 & $128.3 \pm 25.9$ & 0.61 \\
\hline Diastolic BP, mmHg & $77.6 \pm 11.3$ & 0.87 & $81.8 \pm 13.8$ & 0.05 & $79.1 \pm 14.1$ & 1.0 \\
\hline Pulse pressure, $\mathrm{mmHg}$ & $46.6 \pm 16.3$ & 0.03 & $45.2 \pm 16.5$ & 0.15 & $49.1 \pm 20.9$ & 0.78 \\
\hline
\end{tabular}

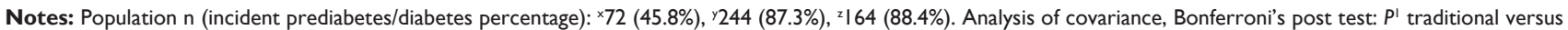
transitional; $P^{2}$ transitional versus modern; $P^{3}$ modern versus traditional.

Abbreviations: SD, standard deviation; BMI, body mass index; FBG, fasting blood glucose; MAP, mean arterial pressure; BP, blood pressure.

index $\geq 29.9 \mathrm{~kg} / \mathrm{m}^{2}$ ) were more commonly found in the transitional and modern communities. However, the mean body mass index did not exceed the normal range (18.5$\left.24.9 \mathrm{~kg} / \mathrm{m}^{2}\right)$ in any of the community categories. Despite this fact, the prevalence of incident prediabetes/diabetes was nearly $50 \%$ in the traditional population category, although they had the lowest mean male and female population body mass index. This is an alarming rate for any population, but particularly striking in a population with poor access to health care, as a result of war, poor transport infrastructure, and continued political instability and conflict.

Notably, although diet and lifestyle vary greatly from the traditional to the modern community, westernization was not a significant risk factor for elevated blood pressure.
However, mean male and female systolic blood pressure levels for each of the three community categories were in the prehypertensive range. ${ }^{15}$ These systolic blood pressure levels are indicative of increased risk for grave consequences, particularly when compounded with a high prevalence of incident prediabetes/diabetes. Additionally, a high pulse pressure of $>50 \mathrm{mmHg}$ was reported by Benetos et al ${ }^{21}$ to be an independent prognostic factor of cardiovascular risk in normotensive men, thereby increasing the severity of risk for men in both traditional and modern communities.

This investigation has the limitations inherent in any cross-sectional study. Specifically, the sample sizes were comparatively small, resulting in wide confidence intervals for some odds ratios. Thus, the strength of the association

Table 2 Odds ratios for fasting blood glucose, pulse pressure, and body mass index according to diet and/or lifestyle modernization/ westernization

\begin{tabular}{|c|c|c|c|c|}
\hline Measured parameter & & Gender & OR & $95 \% \mathrm{Cl}$ \\
\hline \multirow[t]{6}{*}{$\mathrm{FBG}, \mathrm{mg} / \mathrm{dL}^{\mathrm{a}}$} & Diet westernization & Male & 14.85 & $(7.99,27.61)$ \\
\hline & & Female & 8.86 & $(4.91,15.97)$ \\
\hline & Lifestyle westernization & Male & 11.45 & $(4.00,32.78)$ \\
\hline & & Female & 2.27 & $(1.29,4.01)$ \\
\hline & Diet and lifestyle westernization & Male & 37.44 & $(12.20,114.89)$ \\
\hline & & Female & 10.44 & $(4.88,22.32)$ \\
\hline \multirow[t]{6}{*}{ Pulse pressure, $\mathrm{mmH} \mathrm{g}^{\mathrm{b}}$} & Diet westernization & Male & 0.93 & $(0.5 \mathrm{I}, 1.70)$ \\
\hline & & Female & 0.87 & $(0.43,1.77)$ \\
\hline & Lifestyle westernization & Male & 1.33 & $(0.76,2.3 \mathrm{I})$ \\
\hline & & Female & 1.44 & $(0.87,2.38)$ \\
\hline & Diet and lifestyle westernization & Male & 1.46 & $(0.69,3.07)$ \\
\hline & & Female & 1.16 & $(0.50,2.70)$ \\
\hline \multirow[t]{6}{*}{$\mathrm{BMI}, \mathrm{kg} / \mathrm{m}^{2, \mathrm{c}}$} & Diet westernization & Male & 2.10 & $(0.54,8.10)$ \\
\hline & & Female & 9.96 & $(\mathrm{I} .31,75.44)$ \\
\hline & Lifestyle westernization & Male & 1.28 & $(0.48,3.44)$ \\
\hline & & Female & 2.84 & $(1.61,5.02)$ \\
\hline & Diet and lifestyle westernization & Male & 2.75 & $(0.50,15.22)$ \\
\hline & & Female & 18.12 & $(2.24, \mid 46.31)$ \\
\hline
\end{tabular}

Notes: ${ }^{\mathrm{a} B B G}$ was dichotomized according to FBG level for incident prediabetes ( $\geq 100 \mathrm{mg} / \mathrm{dL}$ or $<100 \mathrm{mg} / \mathrm{dL}$ ); ${ }^{\mathrm{b}}$ pulse pressure was dichotomized according to pressure level ( $\geq 50 \mathrm{mmHg}$ or $<49 \mathrm{mmHg}$ ); 'BMl was dichotomized according to body mass index for obesity $\left(\geq 29.9 \mathrm{~kg} / \mathrm{m}^{2}\right.$ or $<29.9 \mathrm{~kg} / \mathrm{m}^{2}$ ).

Abbreviations: FBG, fasting blood glucose; BMI, body mass index; $\mathrm{Cl}$, confidence interval; OR, odds ratio. 
between elevated fasting blood glucose/body mass index levels and diet/diet and lifestyle westernization ratios may be somewhat diminished, particularly with separate male and female data analysis whereby sample sizes were reduced.

Advertisements for the original health screenings were given ubiquitously in each community. However, various selection biases may have arisen. In relation to sample size, there was a great difference in the male/female ratios between traditional, transitional, and modern communities. The timing of the screenings may have acted as an unintentional selection bias. Due to the required overnight fast, health screenings were completed during the morning hours. Also being the coolest part of the day, the majority of the women's outdoor household responsibilities, eg, farming, water-gathering, and food preparation, are usually completed before the temperature rises. With a change in lifestyle and/or diet, women's schedules became more flexible.

An inadvertent selection bias towards unhealthy subjects may have arisen owing to the current health care system in the DRC. This system is based on fees for service, so individuals are often forced to suffer an illness until family and/or friends can raise the money to pay for medical attention. Asymptomatic individuals, who had either previous experience with diabetic family members or previous exposure to facts about diabetes, may have been overly attracted to participate in the screening to receive free testing to rule out the disease. Similarly, individuals with some questionable symptoms may have been drawn to participate at a higher rate than the normal population, in order to have free diagnostics and circumvent the cost for the same at a health care center.

Despite its limitations, this study is a valuable evaluation of the association between the level of community diet and/or lifestyle westernization and cardiovascular risk factors, such as fasting blood glucose levels, body mass index, and blood pressure in the DRC, an economically disadvantaged country.

In summary, this study shows that there is a higher than expected prevalence of incident prediabetes and diabetes in the adult DRC population, without a clear association with risk factors pertaining to diet, level of physical activity, body mass index, and blood pressure. There is a need for diagnostic testing for diabetes in westernized DRC populations because the disease falls within estimated statistics. ${ }^{5}$ However, it is critical that all future testing includes populations in unchanged environments. Support is also needed to test simultaneously for other cardiovascular diseases and risk factors, including prehypertension/hypertension, elevated pulse pressure, malaria status, and liver injury, because they are influential in diabetes onset and/or progression.

\section{Acknowledgments}

We would like to thank Dr Judith Washington at California State University, Dominquez Hills and Dr Kwame Osei at The Ohio State University for their editorial assistance. This work was supported in part by Group de Reflection, Actions, et Etude de Culture and a National Institutes of Health grant T32 HL 007089.

\section{Disclosure}

The authors report no conflicts of interest in this work.

\section{References}

1. Marshall MC Jr Diabetes in African Americans. Postgrad Med J. 2005;81:734-740.

2. Osei K, Schuster DP, Amoah AG, Owusu SK. Diabetes in Africa. Pathogenesis of type 1 and type 2 diabetes mellitus in sub-Saharan Africa: implications for transitional populations. $J$ Cardiovasc Risk. 2003; 10:85-96.

3. Schulz LO, Bennett PH, Ravussin E, et al. Effects of traditional and western environments on prevalence of type 2 diabetes in Pima Indians in Mexico and the US Diabetes Care. 2006;29:1866-1871.

4. Popkin BM. Global nutrition dynamics: the world is shifting rapidly toward a diet linked with noncommunicable diseases. Am J Clin Nutr. 2006;84:289-298.

5. King H, Aubert RE, Herman WH. Global burden of diabetes, 19952025: prevalence, numerical estimates, and projections. Diabetes Care. 1998;21:1414-1431.

6. American Diabetes Association. Standards of medical care in diabetes 2007. Diabetes Care. 2007;30(Suppl 1):S4-S41.

7. Rotimi CN, Chen G, Adeyemo AA, et al. A genome-wide search for type 2 diabetes susceptibility genes in West Africans: the Africa America Diabetes Mellitus (AADM) Study. Diabetes. 2004;53:838-841.

8. Mbanya JC, Ngogang J, Salah JN, Minkoulou E, Balkau B. Prevalence of NIDDM and impaired glucose tolerance in a rural and an urban population in Cameroon. Diabetologia. 1997;40:824-829.

9. Vikram NK, Pandey RM, Misra A, Sharma R, Devi JR, Khanna N. Non-obese (body mass index $<25 \mathrm{~kg} / \mathrm{m}^{2}$ ) Asian Indians with normal waist circumference have high cardiovascular risk. Nutrition. 2003;19: 503-509.

10. Kamadjeu RM, Edwards R, Atanga JS, Kiawi EC, Unwin N, Mbanya JC. Anthropometry measures and prevalence of obesity in the urban adult population of Cameroon: an update from the Cameroon Burden of Diabetes Baseline Survey. BMC Public Health. 2006;6:228.

11. Motala AA, Esterhuizen T, Gouws E, Pirie FJ, Omar MA. Diabetes and other disorders of glycemia in a rural South African community: prevalence and associated risk factors. Diabetes Care. 2008;31: $1783-1788$.

12. Njelekela MA, Mpembeni R, Muhihi A, et al. Gender-related differences in the prevalence of cardiovascular disease risk factors and their correlates in urban Tanzania. BMC Cardiovasc Disord. 2009;9:30.

13. Cooper RS, Rotimi CN, Kaufman JS, et al. Prevalence of NIDDM among populations of the African diaspora. Diabetes Care. 1997;20: 343-348.

14. Dandona P, Chaudhuri A, Aljada A. Endothelial dysfunction and hypertension in diabetes mellitus. Med Clin North Am. 2004;88: 911-931. 
15. Chobanian AV, Bakris GL, Black HR, et al. The Seventh Report of the Joint National Committee on Prevention, Detection, Evaluation, and Treatment of High Blood Pressure: the JNC 7 report. JAMA. 2003; 289:2560-2572.

16. Refugee Council Online. A guide to Congolese cultural and social norms. 2004. Available from: http://www.refugeecouncil.org.uk/practice/advisers/cultural_norms. Accessed July 1, 2011.

17. Congolese Community Profile. 2006. Available from: http://www.immi. gov.au/living-in-australia/delivering-assistance/government-programs/ settlement-planning/community-profiles.htm. Accessed July 1, 2011.

18. Prentice AM, Moore SE. Early programming of adult diseases in resource poor countries. Arch Dis Child. 2005;90:429-432.
19. Vázquez BY, Martini J, Tsai AG, Johnson PC, Cabrales P, Intaglietta M. The variability of blood pressure due to small changes of hematocrit. Am J Physiol Heart Circ Physiol. 2010;299:H863-H867.

20. Morrison EY, Ragoobirsingh D, Peter SA. The unitarian hypothesis for the aetiology of diabetes mellitus. Med Hypotheses. 2006;67: 1115-1120.

21. Benetos A, Safar M, Rudnichi A, et al. Pulse pressure: a predictor of long-term cardiovascular mortality in a French male population. Hypertension. 1997;30:1410-1415.

\section{Publish your work in this journal}

Vascular Health and Risk Management is an international, peerreviewed journal of therapeutics and risk management, focusing on concise rapid reporting of clinical studies on the processes involved in the maintenance of vascular health; the monitoring, prevention and treatment of vascular disease and its sequelae; and the involvement of metabolic disorders, particularly diabetes. This journal is indexed on PubMed Central and MedLine. The manuscript management system is completely online and includes a very quick and fair peer-review system, which is all easy to use. Visit http://www.dovepress.com/ testimonials.php to read real quotes from published authors.

Submit your manuscript here: http://www.dovepress.com/vascular-health-and-risk-management-journal 